\title{
Management of Chronic Hyperkalemia in Patients With Chronic Kidney Disease: An Old Problem With News Options
}

\author{
Enrique Morales ${ }^{1,2,3 *}$, Paolo Cravedi ${ }^{4}$ and Joaquin Manrique ${ }^{5,6}$ \\ ${ }^{1}$ Department of Nephrology, Hospital Universitario 12 de Octubre, Madrid, Spain, ${ }^{2}$ Instituto de Investigación Hospital \\ Universitario 12 de Octubre (imas12), Madrid, Spain, ${ }^{3}$ Department of Medicine, Universidad Complutense de Madrid, \\ Madrid, Spain, ${ }^{4}$ Department of Medicine, Icahn School of Medicine at Mount Sinai, New York, NY, United States, \\ ${ }^{5}$ Nephrology Department, Complejo Hospitalario de Navarra, Pamplona, Spain, ${ }^{6}$ Navarra Institute for Health Research, \\ IdiSNA, Pamplona, Spain
}

\section{OPEN ACCESS}

Edited by:

Carlo Garofalo,

Università della Campania Luigi Vanvitelli, Italy

Reviewed by:

Giuseppe Conte,

University of Campania Luig

Vanvitelli, Italy

Silvio Borrelli,

Università della Campania Luig

Vanvitelli, Italy

*Correspondence:

Enrique Morales

emoralesr@senefro.org

Specialty section:

This article was submitted to

Nephrology,

a section of the journal

Frontiers in Medicine

Received: 14 January 2021

Accepted: 04 May 2021

Published: 04 June 2021

Citation:

Morales E, Cravedi $P$ and Manrique $J$

(2021) Management of Chronic

Hyperkalemia in Patients With Chronic

Kidney Disease: An Old Problem With

News Options. Front. Med. 8:653634.

doi: 10.3389/fmed.2021.653634
Hyperkalemia is one of the main electrolyte disorders in patients with chronic kidney disease (CKD). The prevalence of hyperkalemia increases as the Glomerular Filtration Rate (GFR) declines. Although chronic hyperkalemia is not a medical emergency, it can have negative consequences for the adequate cardio-renal management in the medium and long term. Hyperkalemia is common in patients on renin-angiotensin-aldosterone system inhibitors (RAASi) or Mineralocorticoid Receptor Antagonists (MRAs) and can affect treatment optimization for hypertension, diabetes mellitus, heart failure (HF), and CKD. Mortality rates are higher with suboptimal dosing among patients with CKD, diabetes or HF compared with full RAASi dosing, and are the highest among patients who discontinue RAASis. The treatment of chronic hyperkalemia is still challenging. Therefore, in the real world, discontinuation or reduction of RAASi therapy may lead to adverse cardiorenal outcomes, and current guidelines differ with regard to recommendations on RAASi therapy to enhance cardio and reno-protective effects. Treatment options for hyperkalemia have not changed much since the introduction of the cation exchange resin over 50 years ago. Nowadays, two new potassium binders, Patiromer Sorbitex Calcium, and Sodium Zirconium Cyclosilicate (SZC) already approved by FDA and by the European Medicines Agency, have demonstrated their clinical efficacy in reducing serum potassium with a good safety profile. The use of the newer potassium binders may allow continuing and optimizing RAASi therapy in patients with hyperkalemia keeping the cardio-renal protective effect in patients with CKD and cardiovascular disease. However, further research is needed to address some questions related to potassium disorders (definition of chronic hyperkalemia, monitoring strategies, prediction score for hyperkalemia or length for treatment).

Keywords: hyperkalemia, chronic kidney disease, RAASi, potassium binders, patiromer, zirconium 


\section{INTRODUCTION}

Potassium regulates many biological processes and plays a main role in human physiology. Among the total body electrolyte composition, $2 \%$ potassium resides in extracellular compartment and $98 \%$ in the intracellular space. Vital physiological processes are based on the balance of potassium regulation, including acid-base homeostasis, systemic blood pressure control and vascular tone, hormone secretion, carbohydrate metabolism, gastrointestinal motility, fluid and electrolyte equilibrium, the resting cellular-membrane potential and action potentials in neuronal, muscular, and cardiac tissue $(1,2)$. An average adult has approximate $50 \mathrm{mmol}$ of potassium per $\mathrm{kg}$, meaning 3,500 mmol of total body potassium. The normal kidney maintains normal potassium homeostasis regardless of the total amount of dietary intake. Approximately $90 \%$ of the daily potassium intake is excreted in the urine; the rest is excreted by the gastrointestinal tract, leading a $<10 \%$ of variations in the plasma potassium level during the course of a day. Fresh fruits and vegetables, are considered healthy choices for most people and they are associated with a less renal complications except for hyperkalemia (3). Nevertheless, among patients with chronic kidney disease (CKD), a higher dietary potassium intake may be associated with a higher risk of kidney disease progression (4).

Potassium disorders are common in patients with CKD, due to low glomerular filtration rate (GFR) and tubular disorders and represent a potentially fatal condition. Hyperkalemia represents a frequent complication of $\mathrm{CKD}$ progression, limiting the therapeutic strategies options recommended for treatment and prevention of cardiovascular disease (CVD), including reninangiotensin-aldosterone inhibitors (RAASi) (5). An important CKD-related condition that contributes to hyperkalemia is metabolic acidosis, which causes a shift of potassium from the intracellular to the extracellular space (6). An unmet need exists for hyperkalemia management in the daily setting of special populations as CKD patients. The use of potassium binders has been controversial due to tolerability and safety profile, therefore new released, Patiromer and Zirconium, rather than the classic Sodium Polystyrene Sulfonate (SPS) could represent a strategy for the optimal manage of potassium disorders.

\section{CLASSIC FEEDBACK REGULATION AND FEEDFORWARD CONTROL: TWO MECHANISMS OF POTASSIUM REGULATION}

Dietary potassium intake initiates both increased potassium excretion and sequestration in liver and skeletal muscle, an effect drived by insulin, catecholamines, alkalosis, and mineralocorticoids. Postprandial insulin not only regulates the serum glucose concentrations but also shifts dietary potassium into cells until the kidney starts potassium excretion. Kaliuresis is driven by two mechanisms, depending on the plasma potassium level (the classic feedback regulation) or independent of the plasma potassium level (feedforward regulation) (5). The healthy kidney has the capacity to excrete high amounts of potassium.
In the absence of CKD, humans can intake very large amounts without developing clinically significant hyperkalemia. If the quantity of released potassium is sufficient to increase the plasma potassium level, the feedback system is activated. The potassium is freely filtered by the glomerulus and almost completely reabsorbed in the tubule, just a small portion reaches the distal nephron. A high potassium dietary intake is related to a inhibitory effect on sodium reabsorption in the proximal tubule and the thick ascending limb, facilitating increased delivery of $\mathrm{Na}^{+}$to the aldosterone-sensitive distal nephron (ASDN), running a potassium fine regulation (1). A potassium sensor in the distal tubule has also been described as complementary mechanism in the potassium regulation.

Two mechanisms have been proposed as the major drivers for the proximal tubule reabsorption of $60-75 \%$ of filtered potassium are solvent drag and electrodiffusion. Several co-transporters and ion channels are involved in the complex regulatory reabsorption system of the $15-20 \%$ of filtered potassium in the thick ascending limb of the loop of Henle. The best characterized is the sodium potassium chloride cotransporter also known as NKCC2 (7). NKCC2 has one of the highest overall reabsorptive capacities in the kidney. The distal convoluted tubule mediates reabsorption of 5-10\% of filtered potassium. In the early segment of the distal convoluted tubule, potassium transport is driven exclusively by the thiazide-sensitive sodium chloride cotransporter, whereas in the later segment of the ASDN, the epithelial sodium channel also participates. Three main factors regulate potassium secretion in the ASDN: (1) sodium load, (2) fluid flow rate, and (3) aldosterone and catecholamines (7).

Potassium homeostasis is regulated by renal and extrarenal mechanisms. To enhance the ability to eliminate potassium, there is a complementary mechanism called the "feedforward control." As the GFR declines, potassium excretion is compensated in the remnant functional kidney by enhancing its ability excreting this excess of potassium (1). It is also well-described that hyperkalemia does not appear until GFR reaches the threshold of $15 \mathrm{ml} / \mathrm{min}$, earlier if aldosterone dysfunction is associated. Beyond this adaptive response, extra-renal contribution to potassium handling, especially colonic excretion, becomes critical to prevent acute or chronic hyperkalemia and makes a substantial contribution to potassium homeostasis in patients with CKD (8). Potassium homeostasis in the bowel is modulated due to an enteric sensing system (gut factor), that enhances kaliuresis once potassium enters the intestine, the feedforward system initiated at splanchnic receptors provides maintenance of total body potassium levels within narrow limits after the ingestion of a meal $(2,5)$ (Figure 1). There are two compensatory mechanisms in the colon in response to elevated serum potassium levels in patients with CKD: passive secretion which is responsible for net colonic potassium secretion, basically in the distal colon, and active secretion, that occurs throughout the colon and mechanistically follows the "pump leak" model (basolateral uptake of potassium via $\mathrm{Na} / \mathrm{K}$ pump, $\mathrm{Na} / \mathrm{K} / \mathrm{Cl}$ cotransporter and efflux of potassium through BK channels) (9) (Figure 2). Conversely, during fasting, potassium is released from intracellular stores (liver, muscles). Both feedback and feedforward control work together to maintain potassium 
and sodium homoeostasis (10). Daily potassium intake, renal management and enteric sensor are not the only players in the potassium homeostasis. There is a central circadian clock that regulates the nightly and daily kaliuresis. This rhythm synchronizes the renal tubule cells with the brain, and increases excretion during the active daylight phase and diminishes it during the inactive nighttime phase, regardless from activity, posture or dietary intake (2).

Disorders of potassium balance are common due to changes in dietary intake, GFR, or physiological management (renal and gastrointestinal) among different clinical settings, as CKD patients, renal transplantation (RT), resistant hypertension, or cardiorenal syndrome. The use of otherwise recommended medication like RAASi or MRAs could be critical in the incidence and severity of hyperkalemia.

Traditional dietary recommendations to CKD patients limit the intake of fruits and vegetables because of their high potassium content. However, there is a controversy based on to the benefits derived from a fundamentally vegetarian diet (3). Western diets are largely acid-producing since they are deficient in fruits and vegetables and rich in animal proteins that can induce metabolic acidosis in CKD patients. Thus, diets rich in vegetables and fruits might lower the dietary acid load and induce similar beneficial results as an alkali therapy in CKD patients $(11,12)$.

\section{CHRONIC HYPERKALEMIA IN PATIENTS WITH KIDNEY DISEASE}

\section{Hyperkalemia in Patients With CKD Non-dialysis}

Studies in patients with CKD have shown a remarkable frequency in hyperkalemia in advanced CKD stages, hyporreninemic hypoaldosteronic diabetic patients, renal transplantation (RT), and patients with RAAS inhibition $(4,6)$. Available information shows prevalence percentages ranging from 5 to $20 \%$ depending on the stage of CKD (13). The burden of hyperkalemia is remarkable not only in terms of prevalence, but also in terms of patient survival even for serum potassium levels only moderately increased $(14,15)$. Compensatory mechanisms may help improving tolerance to hyperkalemia in patients with CKD and a J-shaped correlation was found between serum potassium and overall mortality risk in non-dialysis patients (16). Moreover, new onset or persistence of mild-to-moderate hyperkalemia (potassium 5.0-6.0 mmol/L) during 12 months of observation significantly increased by $30 \%$ the risk of End Stage Renal Disease (ESRD) $(4,17,18)$. It has been suggested that CKD patients adapt to elevated potassium concentrations through modifications in gastrointestinal secretions which may favor intracellular potassium storage, or by increasing insulinmediated intracellular potassium uptake in splanchnic and peripheral muscle tissues (19). On the other hand, relevant are also the related economic costs that double in the presence of persistent hyperkalemia (20). In a recent retrospective cohort study of 1,499 patients with chronic hyperkalemia and CKD, heart failure or diabetes mellitus followed up for 36 months, the annual healthcare cost per patient with severe hyperkalemia has calculated as double compared to mild hyperkalemia (21).

\section{Hyperkalemia in Patients With Renal Transplantation}

Hyperkalemia is a common complication in RT with a reported incidence ranging from 25 to $44 \%$ in RT on calcineurin inhibitors (CNIs) (22). It is a life-threatening complication that may increase the length of stay (23). Hyperkalemia in the RT is usually seen in association with renal tubular acidosis and can occur even without insulin deficiency, metabolic acidosis, decreased eGFR or decreased distal sodium delivery. Insulinopenia or insulin resistance can disturb the shifting of potassium and glucose from the extracellular to the intracellular compartment and developing hyperkalemia in the post-transplant setting, especially in insulin dependent diabetics (22). Also the medications used post-transplant has been described as a major cause for posttransplant hyperkalemia in RT, even in those with a well-working graft. As mentioned above, CNIs are considered the major players in the development of hyperkalemia in the RT (24). The use of trimethoprim in standard doses can contribute to hyperkalemia by ENaC blockade. The use of RAASi is recommended after transplantation associated to a better patient and graft survival in RT, but the risk of life-threatening hyperkalemia is twice as the risk for recipients not on these medications (25). Table $\mathbf{1}$ shows the most recent options of treatment of hyperkalemia in RT, highlighting the scarce number of patients included in various studies, especially with the new potassium binders.

\section{Hyperkalemia in Patients With Resistant Hypertension}

Resistant hypertension (RHT) is defined by the failure of the recommended treatment strategies (at least three drugs, including a diuretic) to reduce systolic (SBP) and diastolic blood pressure (DBP) values to $<140 \mathrm{mmHg}$ and/or $<90 \mathrm{mmHg}$ (30). The PATHWAY-2 randomized trial suggested that RHT is commonly a salt-retaining state, most likely due to inappropriate aldosterone secretion (31). In accordance with these findings, in recent years, an increasing body of evidence has shown a beneficial effect of MRAs, such as eplerenone and spironolactone, in improving BP control in patients with RHT. A recent metaanalysis based on data from multiple RCTs provides the evidence that add-on use of spironolactone in patients with RHT is effective in lowering SBP and DBP (32). Nevertheless, the hyperkalemic effect of MRAs in the treatment of hypertension limits their use in patients with advanced CKD. The latest guidelines from the European Society of Hypertension and the American Heart Association established that, besides optimal doses or best tolerated doses of an optimal therapy, the fourthline treatment should involve a blockade of aldosterone through the use of MRAs $(30,33)$. However, it is suggested that the use of spironolactone must be restricted to patients with an eGFR $>45 \mathrm{~mL} / \mathrm{min}$ and a potassium $<4.5 \mathrm{mmol} / \mathrm{L}$. For these reasons, it is important to provide the nephrologist with tools to control potassium while implementing the cardiology guidelines in patients with CKD and RHT. Recently, the AMBER study 


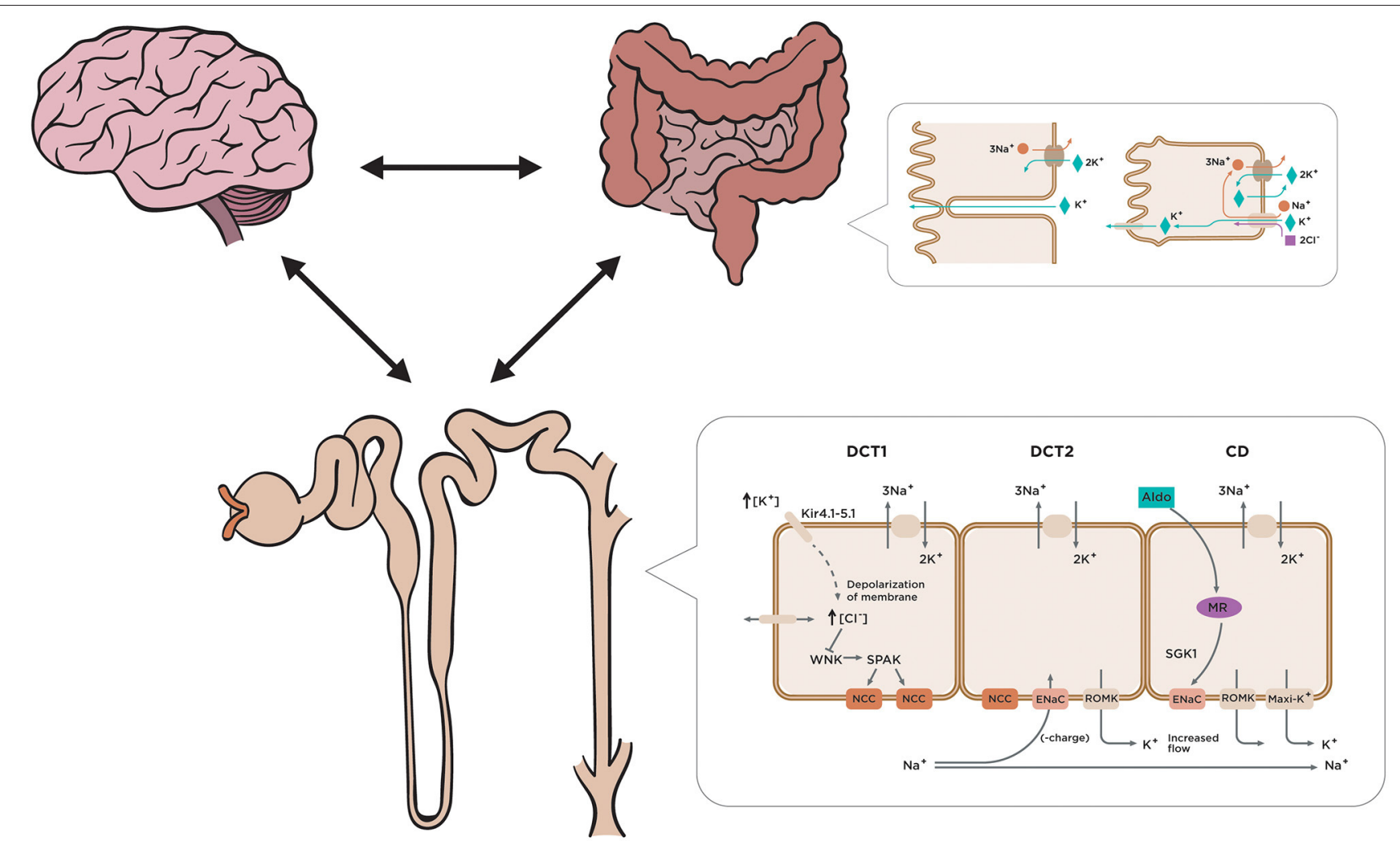

FIGURE 1 | Regulation of external and internal potassium balance. So-called feed-forward control refers to a potassium control pathway that responds to a pre-determined signal from the organism and is highly relevant to the mechanism of additional potassium regulation. The brain generates a regulatory circuit with the kidney and the colon that anticipates the presentation of food. Gastrointestinal-renal signals with a kaliuretic effect are generated, which will be able to mediate renal potassium elimination independent of changes in serum potassium and aldosterone concentration. Several co-transporters and ion channels are involved in the complex regulatory system of potassium reabsorption. The distal convoluted tubule mediates reabsorption of $5-10 \%$ of filtered potassium. Increased plasma $\mathrm{K}^{+}$ concentration depolarizes cells in the proximal portion of the distal convoluted tubule (DCT1) through effects dependent on the potassium. Increased Na ${ }^{+}$delivery and flow to the downstream distal portion of the DCT where aldosterone sensitivity begins (DCT2, connecting tubule, and collecting duct) along with increased aldosterone levels drive potassium secretion.

has suggested that Patiromer enables the use of spironolactone, which effectively lowers systolic blood pressure in patients with RHT and CKD. Persistent spironolactone enablement in this population of patients has clinical relevance for the treatment of RHT (34).

\section{WHAT ARE THE CONSEQUENCES OF DECREASING OR DISCONTINUING RAAS INHIBITORS?}

The renoprotective effects of RAASi should be balanced against the associated risk of hyperkalemia, especially in patients with CKD. Although these drugs have shown an important benefit in patients with $\mathrm{CKD}$, diabetic renal disease, $\mathrm{HF}$ and reduced ejection fraction (HFrEF) (35) and RT, hyperkalemia limits its use contributing to treatment withdrawal or underprescription $(6,36)$.

Current nephrology guidelines recommend RAASi as the primary therapeutic tool in patients with urine albumin excretion $>300 \mathrm{mg} / 24 \mathrm{~h}$ or proteinuria $>500 \mathrm{mg} / 24 \mathrm{~h}$ based on the proven renoprotective efficacy of these agents in proteinuric patients (37). RAASi enable preserving kidney function and delay the progression to ESRD in CKD (37, 38). Nevertheless, side effects limit their use, particularly associated to diuretics (39), dual blockade of RAAS ["Ongoing Telmisartan Alone and in combination with Ramipril Global Endpoint Trial," ONTARGET (40), or "Aliskiren Trial in Type 2 Diabetes Using Cardiorenal Endpoints," ALTITUDE] (41, 42), or neprylisin inhibitors (43). Hyperkalemia is more common than acute kidney injury (AKI) with an incidence ranging from 5 to $40 \%$, and, moreover, patients who would otherwise benefit from RAASi either do not receive these medications, receive suboptimal doses, or discontinue therapy (44). An observational retrospective Japanese cohort study showed that $54 \%$ of patients discontinued RAASi after hyperkalemia (45). Controversy came up with the VA-NEPHRON-D trial that showed a strong trend to lowering the risk of renal disease progression with dual RAAS blockade vs. monotherapy (40). In the same way, MRA therapy could offer an additive proteinuria lowering effect but, like the dual blockage, increases the risk of hyperkalemia (46). Mortality rates are higher with 

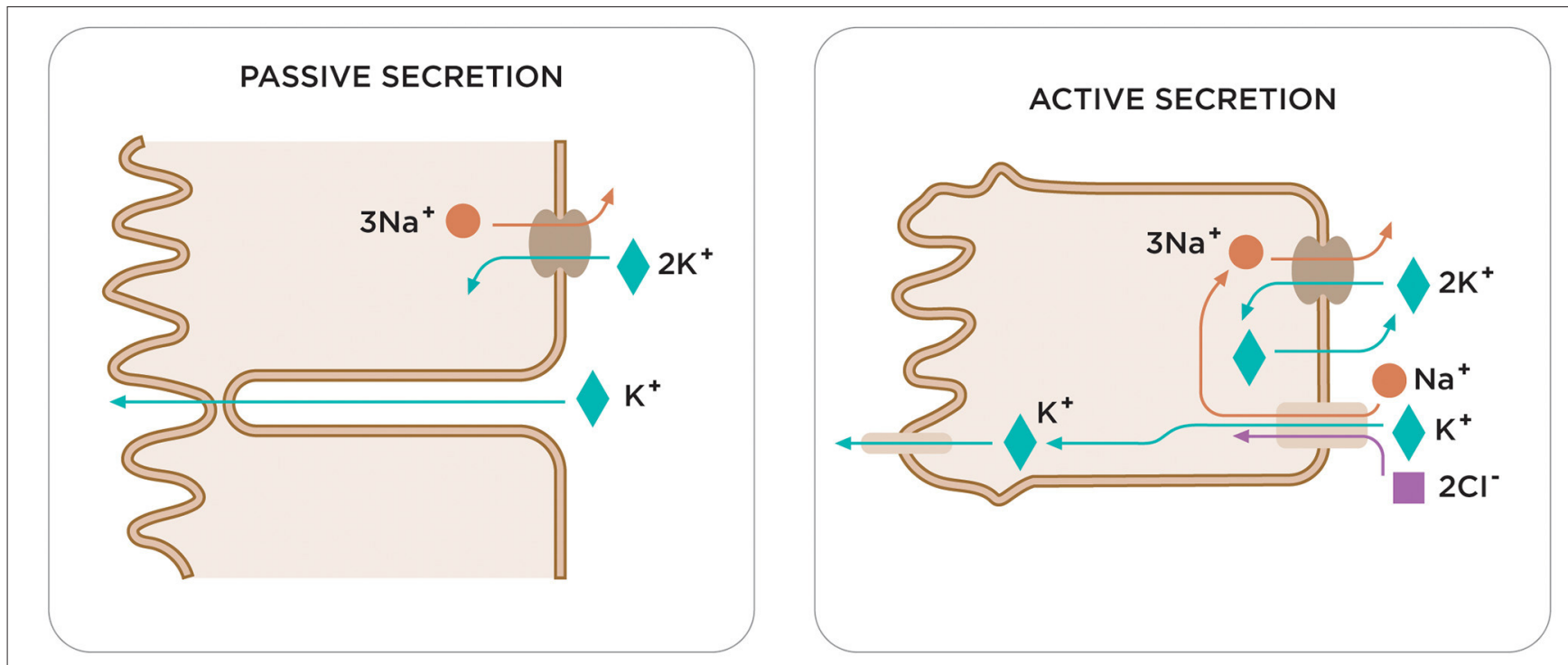

FIGURE 2 | Two compensatory mechanisms in the colon respond to elevated serum potassium levels in patients with CKD. Current studies highlight the existence of a feed-forward control in the regulation of potassium homeostasis, capable of causing rapid changes in renal potassium excretion. Among the different elements of this feed-forward control, the colon plays a fundamental role in the regulation of potassium. It is worth noting the different transport capacity of the potassium in the various segments of the colon or the different expression or activity of potassium channels on the membrane apical of the colon (BK channels). Although the role of the colon in excretion of potassium is not well-known yet, recent studies have found that in CKD the colon is responsible for a considerable increase in potassium removal, which is attributed to an increase in activity of the BK channels. There are two compensatory mechanisms in the colon in response to elevated serum potassium levels in patients with CKD: passive and active secretion.

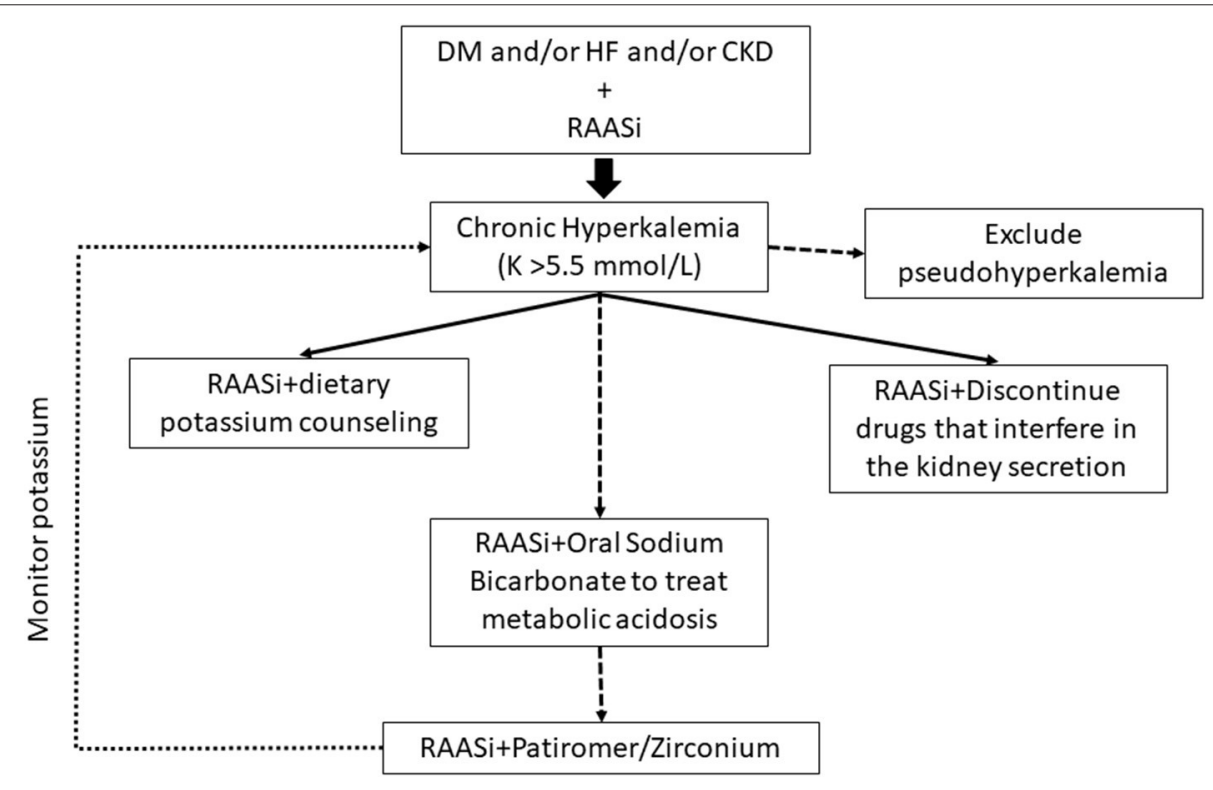

FIGURE 3 | Treatment algorithm for chronic hyperkalemia. Current recommendations regarding the management of chronic hyperkalemia (long-term elevated serum potassium) include the management of diuretics, modification of RAASi dose, treatment of metabolic acidosis with sodium bicarbonate, and removal of other hyperkalemia-causing medications. A team approach for chronic hyperkalemia, primary care physicians, nurses, pharmacists, or dietitians is optimal. The initiation of potassium binding agents should be considered in patients with chronic hyperkalemia despite optimized diuretic therapy and correction of metabolic acidosis. CKD, chronic kidney disease; DM, Diabetes Mellitus; HF, hearth failure; K, potassium; RAASi, renin-angiotensin-aldosterone system inhibitors.

suboptimal dosing/discontinuation of RAASi among patients with CKD, diabetes or HF compared with those with full RAASi dose $(19,47)$.
In routine clinical practice, we faced the conundrum of prescribing RAASi assuming the likelihood of hyperkalemia (up to $54 \%$ ) or avoiding/discontinuing beneficial RAASi therapies. 
TABLE 1 | Clinical studies of Patiromer and SZC in transplant patients.

\begin{tabular}{|c|c|c|c|}
\hline Study & Drug & Population & Primary outcomes \\
\hline Schnelle et al. (26) & Patiromer $8.4 \mathrm{~g}$ daily & $\begin{array}{l}\text { SOT: kidney } 73 \% \text {, liver } 21 \% \text {, } \\
\text { kidney-pancreas } 3 \% \text {, lung } 3 \% \\
N=37\end{array}$ & $\begin{array}{l}\text { Moderate reduction in Potassium } \\
\text { levels at week } 4 \text { and } 12 . \\
\text { Increase of TC levels. }\end{array}$ \\
\hline Lim et al. (27) & Patiromer $8.4-16.8 \mathrm{~g}$ daily & $\begin{array}{l}\text { Kidney transplants } \\
N=17\end{array}$ & $\begin{array}{l}\mathrm{K}<5.2 \mathrm{mmol} / \mathrm{l} \text { at last follow-up (84\%). } \\
\text { Seven patients required TC } \\
\text { dose reduction. }\end{array}$ \\
\hline Rattanavich et al. (28) & Patiromer $8.4-16.8 \mathrm{~g}$ daily & 2 kidney transplants & $\begin{array}{l}\text { Patiromer is effective and does not } \\
\text { affect TC levels. }\end{array}$ \\
\hline Winstead et al. (29) & SZC & $\begin{array}{l}\text { SOT: kidney } 45.7 \% \text {, liver } 40 \% \text {, heart } \\
5.7 \% \text {, kidney-liver } 5.7 \% \text {, kidney-heart } \\
2.9 \% \\
N=35\end{array}$ & $\begin{array}{l}\text { Potassium levels decreased by }-1.3 \\
\mathrm{mmol} / \mathrm{l} \text { from day } 0 \text { to day } 7 \text {. } \\
\mathrm{TC}-0.54 \mathrm{ng} / \mathrm{ml} \text {. }\end{array}$ \\
\hline
\end{tabular}

SOT, Solid Organ Transplantation; SZC, Sodium Zirconium Cyclosilicate; TC, Tacrolimus.

Although hyperkalemia has long been regarded as a reason for RAASi non-prescription, down titration, or discontinuation, it has been disregarded as a major topic in the literature (47). Nevertheless, the gap in information on the incidence of hyperkalemia between the real world and the world of clinical trials is well-known. A recent Portuguese study in patients with HFrEF highlighted their higher risk of developing hyperkalemia associated to comorbidities such as CKD, diabetes, or the use of dual or triple therapy including RAASi and concurrent HF therapy. In the same way the initiation of RAASi compared with calcium channel blockers may confer kidney and cardiovascular benefits among patients with advanced CKD from the Swedish Renal Registry (48). This point emphasizes the need to carry out studies on the impact of the reduction or suspension of RAASi on the prognosis of these patients (41). This significant body of literature highlights the need for a change of therapeutic strategy in maintaining the renal and cardio protection of RAASi in selected population as CKD patients, HF patients or diabetic patients, and the new potassium binders become essential treating hyperkalemia (Figure 3).

\section{TREATMENT OF CHRONIC HYPERKALEMIA: SOMETHING OLD}

In a recent meta-analysis of $1,217,986$ participants in 27 diverse cohorts, hyperkalemia (serum $\mathrm{K} \geq 5.0 \mathrm{mmol} / \mathrm{L}$ ) was associated with significantly higher long-term risk of all-cause and CV mortality, and of ESRD. Although the definition of hyperkalemia is debated, ideal outcomes were observed with serum potassium concentrations of $4-4.5 \mathrm{mmol} / \mathrm{L}$ (15). Chronic management of hyperkalemia usually starts by dietary education and recommendation of a low potassium intake. However, it is well-known the renoprotective effect of potassium supplementation or intake by fruit and vegetable in CKD (49). It is well-known the renoprotective effect of potassium supplementation or intake by fruit and vegetable in CKD. Although the acknowledgment that dietary potassium restriction is a valid strategy to treat acute hyperkalemia, it's been hypothesized that potassium restriction as a general strategy to prevent hyperkalemia in persons with CKD may deprive patients of the beneficial effects associated with potassium-rich diets (9). The "KDIGO 2020 Executive Conclusions on Potassium Hemostasis and Disorders," did not find evidence that increased potassium intake, or liberalization of potassium restrictions, in patients with advanced CKD would be safer (9). The position statement of the Italian Society of Nephrology for Hyperkalemia management in CKD patients state that potassium $\geq 5.0 \mathrm{mmol} / \mathrm{L}$ must be considered pathologic in $\mathrm{CKD}$ and require careful follow-up and implementation of preventive and therapeutic strategies aimed at maintaining it in the optimal clinical range (50). On this regard, it is important to highlight the role of new potassium binders to overcome potassium restrictions in CKD $(51,52)$.

In healthy subjects the gastrointestinal tract contribution to potassium excretion is minimal (about $10 \%$ of the total), while in the case of kidney disease it may increase until it accounts for $50 \%$ of the total potassium excretion in patients on dialysis. The kidney (feedback control) and the colonic potassium handling (feedforward control) are strictly related, and it has been shown that the potassium enteral load may influence renal excretion (gut-dependent kaliuresis sensor, mentioned above) (53). This potassium secretory capacity makes of the colon a potential target for therapies aimed at treating and preventing hyperkalemia in patients with advanced CKD. Potassium binders make potassium unavailable in the distal colon for absorption by trapping it within the binder molecule, which is then excreted with the feces. Historically, the only options for promoting potassium elimination by the gastrointestinal tract have been limited to the "old" sodium cation-exchanging resin, sodium polystyrene sulfonate (SPS, Kayexalate; Sanofi-Aventis US LLC, Bridgewater, NJ). SPS was approved in 1958 but despite its common use, there is limited evidence demonstrating the effectiveness and safety in controlled studies (Table 2). The mixture with sorbitol at high concentrations, moreover, carries a risk of colonic necrosis and other serious GI adverse events $(60,61)$. A significant increase in the incidence of hospitalization for serious adverse GI events has been recently described in a large cohort of SPS users, when compared with matched non-users (62). Moreover, SPS initiation in adults with CKD stages has been associated with a higher 
TABLE 2 | Clinical studies of sodium and calcium polysterene sulfonate (54).

\begin{tabular}{|c|c|c|c|}
\hline Study & Drug & Population & Primary outcomes \\
\hline $\begin{array}{l}\text { Phase 4, randomized, } \\
\text { double-blind, placebo } \\
\text { controlled; (55) }\end{array}$ & SPS $30 \mathrm{~g}$ or placebo QD & $\begin{array}{l}\text { Pre-dialysis (stages } 3-5 \text { ), EGFR }<40 \\
\mathrm{ml} / \mathrm{min} \text { and potassium } 4.5-5.5 \\
\mathrm{mmol} / \mathrm{L} \\
\mathrm{N}=33\end{array}$ & $\begin{array}{l}\text { Mean change in serum Potassium } \\
\text { was superior to placebo in reducing } \\
\text { serum potassium over } 7 \text { days vs. } \\
\text { placebo: }-1.04 \mathrm{mmol} / \mathrm{l}(-1.37 \text { to } \\
0.71 \mathrm{mmo} / \mathrm{L})\end{array}$ \\
\hline $\begin{array}{l}\text { Effect of SPS in CKD; } \\
(56)\end{array}$ & $\begin{array}{l}4 \text { single-dose SPS and } \\
\text { placebo on } 5 \text { different test } \\
\text { days }\end{array}$ & $\begin{array}{l}\text { Patients with CKD } \\
N=6\end{array}$ & $\begin{array}{l}\text { No significant effect of SPS on total } \\
\text { potassium output }\end{array}$ \\
\hline $\begin{array}{l}\text { Randomized and } \\
\text { crossover design; (57) }\end{array}$ & $\begin{array}{l}\text { CPS vs. SPS therapy for } 4 \\
\text { weeks }\end{array}$ & $\begin{array}{l}\text { Pre-dialysis CKD } 4-5 \text { and Potassium } \\
>5 \mathrm{mmol} / \mathrm{L} \\
N=20\end{array}$ & $\begin{array}{l}\text { CPS safer for the treatment of } \\
\text { hyperkalemia in pre-dialysis patients, } \\
\text { because it did not induce } \\
\text { hyperparathyroidism or volume } \\
\text { overload }\end{array}$ \\
\hline $\begin{array}{l}\text { Randomized Control } \\
\text { trial; (58) }\end{array}$ & CPS vs. SPS therapy & $\begin{array}{l}\text { CKD stages } 1-4 \text { and Potassium }>5.2 \\
\mathrm{mmol} / \mathrm{L} \\
N=97\end{array}$ & $\begin{array}{l}\text { Both CPS and SPS can be used } \\
\text { effectively for reducing hyperkalemia } \\
\text { of CKD. CPS showed fewer side } \\
\text { effects as compared to SPS }\end{array}$ \\
\hline $\begin{array}{l}\text { Prospective, } \\
\text { Randomized, } \\
\text { Crossover Study; (59) }\end{array}$ & CPS 3-week $\times 5$ g/day & $\begin{array}{l}\text { HD patients and Potassium }>5.5 \\
\mathrm{mmol} / \mathrm{L} \\
N=58\end{array}$ & $\begin{array}{l}\text { CPS decreases serum levels of } \\
\text { potassium and phosphorus in HD } \\
\text { patients with interdialytic } \\
\text { hyperkalemia. } \\
\text { CPS does not induce volume } \\
\text { overload or disrupt } \\
\text { electrolyte balance. }\end{array}$ \\
\hline
\end{tabular}

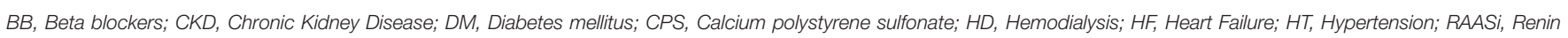
Angiotensin Aldosterone System Inhibitors; SPS, Sodium polystyrene sulfonate; QD, quaque die.

incidence of severe gastrointestinal adverse events, mainly ulcers and perforations, possibly in a dose-dependent manner (63).

In contrast, calcium polystyrene sulfonate (CPS) has long been used for patients with advanced CKD in some parts of the world. It avoids sodium retention and supplements calcium and may have an advantage over SPS. However, few clinical studies have evaluated the efficacy of CPS in the treatment of hyperkalemia (64) (Table 2).

\section{TREATMENT OF CHRONIC HYPERKALEMIA: SOMETHING NEW}

Two new colonic potassium binders have shown efficacy in lowering plasma potassium in recent clinical trials. Sodium Zirconium Silicate (SZC) and Patiromer have been introduced to manage hyperkalemia and promise to be more effective than SPS. In short and long-term studies involving patients on concomitant RAAS therapy, both SZC and Patiromer significantly lowered plasma potassium compared to placebo (Tables 3, 4). By facilitating fecal potassium excretion, these new binders are likely to open new horizon for the treatment and prevention of hyperkalemia in high-risk patients, such as those in therapy with RAASi and/or MRAs. These new potassium binders may allow extending these therapies to patients, in whom concerns with hyperkalemia have limited their use. Patiromer was approved for the treatment of hyperkalemia by the FDA in 2015. Patiromer is a cross-linked polymer of 2-fluoro acrylic acid
(91\%), with divinylbenzenes (8\%) and 1,7-octadiene (1\%). It is used in the form of its calcium salt (ratio 2:1) and with sorbitol, a combination called Patiromer sorbitex calcium. Patiromer works by binding the free potassium ions in the gastrointestinal tract, mainly in the distal colon lumen, and releasing calcium ions for exchange, thus lowering the amount of potassium available for absorption and increasing the amount that is excreted with the feces $(41,79)$.

Under in vitro conditions mimicking the $\mathrm{pH}$ and potassium content of the colon, Patiromer binds 8.5-8.8 mmol of potassium per gram of polymer (80). In healthy volunteers, Patiromer administered for 8 days three times a day, caused a dose-dependent increase in fecal potassium excretion, with a corresponding dose-dependent reduction in urinary excretion (81).

The PEARL HF study explored the safety/efficacy profile of Patiromer in a large population of patients with HF and either a history of hyperkalemia resulting in the discontinuation of RAASi or MRA, or CKD treated with one or more HF therapies. Patiromer was associated with a significantly lower serum potassium levels, a lower incidence of hyperkalemia, and a higher proportion of patients on spironolactone after 4 weeks (65) (Table 3). Patiromer was also tested for 4 weeks in hyperkalemic CKD stage 3-4 patients undergoing stable treatment with one or more RAASi in the OPAL-HK study (66), showing a stable potassium lowering levels in two phases, regardless of age, gender, baseline potassium levels, diabetes, HF and maximal/not maximal RAASi dosage (82). An interesting 
TABLE 3 | Clinical studies of patiromer (54).

Study
PEARL-HF; phase 2,
randomized, double-blind,
placebo-controlled; (65)
OPAL-HK; phase 3,
2 stages:
(1) treatment, single-group,
single-blind
(2) withdrawal, randomized,
single-blind, placebo controlled;
(66)

AMETHYST-DN; phase 2, randomized, open-label; (67)

\section{Drug}

Patiromer $15 \mathrm{~g}$ or placebo BID

(+spironolactone $25 \mathrm{mg} / \mathrm{d})^{\mathrm{a}}$

\author{
Patiromer $4.2 \mathrm{~g}$ (mild hyperkalemia) or \\ $8.4 \mathrm{~g}$ (moderate to severe \\ hyperkalemia) BID
}

Population

$\mathrm{CKD}, \mathrm{HF}$, indication to initiate

spironolactone, potassium of 4.3-5.1

$\mathrm{mEq} / \mathrm{L}$, receiving RAASi or $\mathrm{BB}$

$N=105$

CKD (stage 3-4), eGFR 15 to $<60 \mathrm{ml} / \mathrm{min}$, receiving RAASi and serum potassium levels of 5.1 to $<6.5 \mathrm{mmol} / \mathrm{L}$ $N=237$
Mild hyperkalemia: Patiromer 4.2, 8.4, or $12.6 \mathrm{~g} \mathrm{BID}^{\mathrm{b}}$ Moderate hyperkalemia: patiromer 8.4, 12.6, or $16.8 \mathrm{~g} \mathrm{BID}^{\mathrm{b}}$
Type 2 DM and CKD (eGFR 15-60 ml/min) and serum potassium $<5 \mathrm{mmol} / \mathrm{l}$ with RAASi

$N=306$
Uncontrolled resistant HT and CKD (eGFR $25-45 \mathrm{ml} / \mathrm{min}$ ) and serum potassium 4.3-5.1 $\mathrm{mmol} / \mathrm{L}$

$N=295$

Low ejection fraction heart failure (with or without CKD), receiving beta blocker, with either current hyperkalemia at screening or a history of hyperkalemia in the past year $N=2,400$

Patiromer

ESRD treated $\mathrm{HD}$, two measured pre-dialysis $\mathrm{K}>5.5 \mathrm{mmol} / \mathrm{l}$ or one $\mathrm{K}>6.0$ $\mathrm{mmol} / \mathrm{L}$

$N=40$

SOC or one dose of $25.2 \mathrm{~g}$ oral Patiromer plus SOC

Patiromer, $8.4 \mathrm{~g} / \mathrm{d}$ to start, adjusted to achieve and maintain serum potassium of $3.8-5.0 \mathrm{mmol} / \mathrm{L}$.
Adult patients with ESRD and a serum potassium level of $\geq 6.0 \mathrm{mmol} / \mathrm{L}$

Hyperkalemia (potassium>5.0 mmol/L), receiving $\mathrm{RAASi}, \mathrm{BB}$ or diuretics, $\mathrm{CKD}$ stages 1-5, HF and DM and/or HT $N=112$
Primary outcomes

Mean change in serum Potassium:

$-0.22 \mathrm{mmol} / \mathrm{l}$ with Patiromer

$-0.23 \mathrm{mmol} / \mathrm{l}$ with placebo

Mean difference vs. placebo:

$-0.45 \mathrm{mmol} / \mathrm{L}$

Treatment stage:

Mean change in Potassium at week 4:

Mild hyperkalemia $-0.65 \mathrm{mmol} / \mathrm{L}$

Moderate to severe hyperkalemia -1.23

$\mathrm{mmol} / \mathrm{L}$

Withdrawal stage:

Median change in potassium week 4:

$0 \mathrm{mmol} / \mathrm{l}$ with patiromer

$+0.72 \mathrm{mmol} / \mathrm{l}$ with placebo

Mild hyperkalemia:

Mean change in serum potassium:

$-0.35 \mathrm{mmol} / \mathrm{l}$ with Patiromer $4.2 \mathrm{~g}$

$-0.51 \mathrm{mmol} / \mathrm{l}$ with Patiromer $8.4 \mathrm{~g}$

-0.55 mmol// with Patiromer $12.6 \mathrm{~g}$

Moderate hyperkalemia:

Mean change in serum potassium:

$-0.87 \mathrm{mmol} / \mathrm{I}$ with Patiromer $8.4 \mathrm{~g}$

$-0.97 \mathrm{mmol} / \mathrm{l}$ with Patiromer $12.6 \mathrm{~g}$

-0.92 mmol/l with Patiromer $16.8 \mathrm{~g}$

Patients remaining on spironolactone: $86 \%$ with Patiromer

$66 \%$ with placebo

More patients in Patiromer vs. placebo

with serum potassium $\leq 5.5 \mathrm{mmol} / \mathrm{L}$

Ongoing (NCT03888066)

Ongoing (NCT03781089)

$2 \mathrm{~h}$ post treatment serum potassium with Patiromer was lower than SOC (5.90 vs. $6.51 \mathrm{mmol} / \mathrm{L}$ ) and also $0.61 \mathrm{mmol} / \mathrm{L}$ lower than baseline

From baseline to week 4 , the change in serum potassium was $-0.67 \mathrm{mmol} / \mathrm{l}$ in patients taking RAASi and $-0.56 \mathrm{mmol} / \mathrm{l}$ in patients not taking RAASi not taking RAASi; (41)

CKD, Chronic Kidney Disease; BB, Beta blockers; DM, Diabetes mellitus; ED, Emergency Department; HF, Heart Failure; ESRD, End-Stage Renal Disease; HT, Hypertension; RAASi, Renin Angiotensin Aldosterone System Inhibitors; SOC, Standard of care; quaque die; BID, Bis in die.

a Spironolactone dosage increased to $50 \mathrm{mg} / \mathrm{d}$ after 2 weeks in patients with serum $\mathrm{K}>3.5$ to $\leq 5.1 \mathrm{mmol} / \mathrm{L}$. ${ }^{b}$ Patiromer was titrated to achieve and maintain serum $\mathrm{K} \leq 5.0 \mathrm{mmol} / \mathrm{L}$.

c Spironolactone dosage increased to $50 \mathrm{mg} / \mathrm{d}$ after 2 weeks in patients with serum $\mathrm{K}>3.5$ to $\leq 5.1 \mathrm{mmol} / \mathrm{L}$.

finding of OPAL-HK study was the reduction of aldosterone levels independent of plasma renin activity, hyperkalemia or use of RAASi, followed by a reduction in blood pressure and albuminuria. This finding comes up with the idea that Patiromer may improve cardiovascular risk beyond the reduction in potassium levels (83).

The recent AMBER study, evaluated the use of Patiromer in patients with RHT and CKD. Patiromer allowed to $86 \%$ of the patients to remain on spironolactone with less hyperkalemia after 12 weeks, what has a critical relevance in the treatment of RHT (34). Finally, the ongoing DIAMOND study, that will end in 2022, will determine whether Patiromer treatment of HF subjects with hyperkalemia while receiving RAASi allows to continue RAASi considering not only safety or efficacy endpoints but primary "hard" endpoints (time to the first occurrence of cardiovascular death or hospitalization) (84).

Based on the above-mentioned large trials, Patiromer is recommended at a starting dosage of $8.4 \mathrm{~g}$ once daily, 
TABLE 4 | Clinical studies of SZC (54).

\begin{tabular}{|c|c|c|c|}
\hline Study & Drug & Population & Primary outcomes \\
\hline $\begin{array}{l}\text { Phase } 2 \text { study } \\
\text { randomized, double-blind, } \\
\text { placebo-controlled to } \\
\text { assess safety and efficacy } \\
\text { of SZC; (70) }\end{array}$ & $\begin{array}{l}0.3,3 \text {, or } 10 \mathrm{~g} \text { of } \mathrm{SZC} \text { three } \\
\text { times daily for } 2 \text { Days or } \\
\text { placebo }\end{array}$ & $\begin{array}{l}\text { CKD (eGFR } 30-60 \mathrm{ml} / \mathrm{min}) \text { and } \\
\text { moderate hyperkalemia (5-6 mmol/L), } \\
\mathrm{DM}, \mathrm{HF} \text {, and } \mathrm{HT} \\
N=90\end{array}$ & $\begin{array}{l}\text { From baseline, mean serum potassium was } \\
\text { significantly decreased by } 0.92 \pm 0.52 \mathrm{mmol} / \mathrm{l} \\
\text { at } 38 \mathrm{~h} \text {. } \\
\text { Urinary potassium excretion significantly } \\
\text { decreased with } 10 \mathrm{~g} \text { SZC as compared to } \\
\text { placebo at Day } 2\end{array}$ \\
\hline $\begin{array}{l}\text { DIALIZE; phase 3b, } \\
\text { randomized, double-blind, } \\
\text { placebo-controlled; (71) }\end{array}$ & $\begin{array}{l}\text { SZC } 5,10 \text {, or } 15 \mathrm{~g} \text { or } \\
\text { placebo QD on non-dialysis } \\
\text { days for } 4 \text { weeks. }\end{array}$ & $\begin{array}{l}\text { HD } 3 \text { times, predialysis serum } \mathrm{K}>5.4 \\
\mathrm{mmol} / \mathrm{I} \text { (long interdialytic) and } \mathrm{K}>5 \\
\mathrm{mmol} / \mathrm{I} \text { (short interdialytic) } \\
N=196\end{array}$ & $\begin{array}{l}\text { Maintenance of predialysis serum potassium } \\
4.0-5.0 \mathrm{mmol} / \mathrm{l} \text { during } \geq 3 \text { of } 4 \text { hemodialysis } \\
\text { sessions after long interdialytic interval without } \\
\text { requiring rescue therapy: } \\
41 \% \text { with SZC } \\
1 \% \text { with placebo }\end{array}$ \\
\hline $\begin{array}{l}\text { ENERGIZE; phase 2, } \\
\text { randomized, double-blind, } \\
\text { placebo-controlled; (72) }\end{array}$ & $\begin{array}{l}\text { SZC } 10 \mathrm{~g} \text { (3 doses in } 10 \mathrm{~h}) \\
\text { or placebo }\end{array}$ & $\begin{array}{l}\text { Emergency Department with } \\
\text { potassium level }>5.8 \mathrm{mmol} / \mathrm{l} \\
N=70\end{array}$ & $\begin{array}{l}\text { Mean change in serum Potassium at } 4 \mathrm{~h} \text { : } \\
-0.41 \mathrm{mmol} / \mathrm{l} \text { with } \mathrm{SZC} \\
-0.27 \mathrm{mmol} / \mathrm{l} \text { with placebo } \\
\text { Mean difference vs. placebo: } \\
-0.13 \mathrm{mmol} / \mathrm{l}\end{array}$ \\
\hline $\begin{array}{l}\text { HARMONIZE; phase 3, } \\
\text { 2-stage, randomized, } \\
\text { double-blind, placebo } \\
\text { controlled; (73) }\end{array}$ & $\begin{array}{l}\text { Initial phase (open-label): } \\
\text { SZC } 10 \mathrm{~g} \text { TID for } 48 \mathrm{~h} \\
\text { Maintenance } \\
\text { phase (double-blind): } \\
\text { SZC 5, 10, or } 15 \mathrm{~g} \text { or } \\
\text { placebo QD for } 28 \text { days }\end{array}$ & $\begin{array}{l}\text { CKD }<30 \mathrm{ml} / \mathrm{min} \text { and hyperkalemia } \\
\text { (potassium } 5.1 \mathrm{mmol} / \mathrm{L} \text { ) } \\
N=258\end{array}$ & $\begin{array}{l}\text { Initial phase (open-label): } \\
\text { Mean change in serum potassium over } 48 \mathrm{~h} \text { : } \\
-1.1 \mathrm{mmol} / \mathrm{l} \text { vs. baseline Maintenance } \\
\text { phase (double-blind): } \\
4.8 \mathrm{mmol} / \mathrm{I} \text { with SZC } 5 \mathrm{~g} \mathrm{QD} \\
4.5 \mathrm{mmol} / \mathrm{I} \text { with SZC } 10 \mathrm{~g} \mathrm{QD} \\
4.4 \mathrm{mmol} / \mathrm{I} \text { with SZC } 15 \mathrm{~g} \mathrm{QD} \\
5.1 \mathrm{mmol} / \mathrm{I} \text { with placebo vs. placebo for } \\
\text { each dose }\end{array}$ \\
\hline $\begin{array}{l}\text { Phase } 3 \text { randomized, } \\
\text { double-blind, } \\
\text { placebo-controlled trial; } \\
\text { (74) }\end{array}$ & $\begin{array}{l}\text { Daily SZC }(5,10 \text {, or } 15 \mathrm{~g}) \text { or } \\
\text { placebo for } 28 \text { days }\end{array}$ & $\begin{array}{l}\text { HF patients with potassium } \geq 5.1 \\
\mathrm{mmol} / \mathrm{L} \\
N=94\end{array}$ & $\begin{array}{l}\text { Compared with placebo, all three SZC doses } \\
\text { lowered potassium and effectively maintained } \\
\text { normokalemia for } 28 \text { days without adjusting } \\
\text { RAASi }\end{array}$ \\
\hline $\begin{array}{l}\text { Phase } 3 \text { randomized, } \\
\text { double-blind, two stages, } \\
\text { placebo-controlled trial; } \\
\text { (75) }\end{array}$ & $\begin{array}{l}\mathrm{SZC}(1.25,2.5,5 \text {, or } 10 \mathrm{~g}) \\
\text { or placebo three times daily } \\
\text { for } 48 \mathrm{~h} \\
\text { Initial phase and } \\
\text { maintenance phase }\end{array}$ & $\begin{array}{l}\text { CKD stage } 3 \text {, serum potassium level } \\
5-6.5 \mathrm{mmol} / \mathrm{L} \\
N=735\end{array}$ & $\begin{array}{l}\text { SZC showed a significant reduction in } \\
\text { potassium levels at } 48 \mathrm{~h} \text {, with normokalemia } \\
\text { maintained during } 12 \text { days of maintenance } \\
\text { therapy as compared with placebo }\end{array}$ \\
\hline $\begin{array}{l}\text { Phase 2-3, randomized, } \\
\text { double-blind, } \\
\text { placebo-controlled, } \\
\text { dose-response study; (76) }\end{array}$ & $\begin{array}{l}\text { SZC } 5,10 \mathrm{~g} \text {, or placebo } \\
\text { three times daily for } 48 \mathrm{~h}\end{array}$ & $\begin{array}{l}\text { Japanese adults with hyperkalemia } \\
\text { (Potassium }>5.1 \mathrm{mmol} / \mathrm{L} \text { ) } \\
N=103\end{array}$ & $\begin{array}{l}\text { At } 48 \mathrm{~h} \text {, the proportions of patients with } \\
\text { normokalemia were } 85.3,91.7 \text {, and } 15.2 \% \\
\text { with SZC } 5 \mathrm{~g} \text {, SZC } 10 \mathrm{~g} \text {, and placebo, } \\
\text { respectively }\end{array}$ \\
\hline $\begin{array}{l}\text { ZS-005; phase 3, 2-stage, } \\
\text { open-label; (77) }\end{array}$ & $\begin{array}{l}\text { Correction phase: } \\
\text { SZC } 10 \mathrm{~g} \text { TID for } 24-72 \mathrm{~h} \\
\text { Maintenance phase: } \\
\text { SZC } 5 \mathrm{~g} \text { QD }\end{array}$ & $\begin{array}{l}\text { Hyperkalemia (two consecutive } \\
\text { Potassium }>5.1 \mathrm{mmol} / \mathrm{L} \text { ) } \\
N=751\end{array}$ & $\begin{array}{l}\text { Correction phase: } \\
78 \% \text { of patients had serum Potassium 3.5-5.0 } \\
\text { mmol/l at } 72 \text { h Maintenance phase: } \\
88 \% \text { of patients had serum Potassium }<5.1 \\
\text { mmol// over } 3-12 \text { mo }\end{array}$ \\
\hline $\begin{array}{l}\text { Post-hoc analysis of an } \\
\text { open-label, single-arm trial } \\
\text { compared SZC efficacy } \\
\text { and safety; (78) }\end{array}$ & $\begin{array}{l}\text { SZC } 10 \mathrm{~g} \text { TID for } 24-72 \mathrm{~h} \\
\text { until normokalemia followed } \\
\text { by once daily SZC } 5 \mathrm{~g} \text { for } 12 \\
\text { months }\end{array}$ & $\begin{array}{l}\text { Hyperkalemia (potassium }>5.1 \\
\mathrm{mmol} / \mathrm{L}) \text { and } \mathrm{CKD}(4 \text { and } 5) \text { vs. those } \\
\text { CKD }(1-3)>12 \text { months } \\
N=751\end{array}$ & $\begin{array}{l}\text { Correction Phase: } \\
82 \% \text { of patients achieved normokalemia in } \\
\text { both eGFR within } 24 \mathrm{~h} \text {, } \\
100 \text { and } 95 \% \text { with eGFR }<30 \text { and } \geq 30 \\
\mathrm{~mL} / \mathrm{min} \text {, respectively, within } 72 \mathrm{~h}\end{array}$ \\
\hline PRIORITIZE-HF: Phase 2 & SZC compared to placebo. & $\begin{array}{l}\text { Patients with HF taking RAASi } \\
N=182\end{array}$ & Ongoing (NCT03532009). \\
\hline
\end{tabular}

BB, Beta blockers; CKD, Chronic Kidney Disease; DM, Diabetes mellitus; HF, Heart Failure; HT, Hypertension; RAASi, Renin Angiotensin Aldosterone System Inhibitors.

administered orally, which can be increased by 8.4 -g increments per week, titrated up to a maximum of $25.2 \mathrm{~g}$ once daily (79).

Sodium Zirconium Cyclosilicate (SZC) is the most recently approved potassium binding agent with efficacy and safety established in phase 2 and 3 clinical trials of patients with hyperkalemia and $\mathrm{CKD}, \mathrm{HF}$, and/or diabetes or those receiving
RAASi (Table 4). SZC is a non-absorbed, insoluble, inorganic crystal that selectively entraps potassium in the GI tract in exchange for sodium and hydrogen. Because of its high selectivity for potassium, SZC may bind it throughout the entire GI tract, and may produce a rapid potassium lowering effect. It has been estimated that $1 \mathrm{~g}$ of SZC binds about 3 
mmol of potassium, and its activity begins within $1 \mathrm{~h}$ after taking (85).

SZC has been evaluated in several randomized trials and open-label long-term observational studies (Table 4). In the HARMONIZE study, hyperkalemic patients with CKD, HF, or diabetes received SZC for $48 \mathrm{~h}$ and showed a significant reduction in potassium levels. Ninety-eight percentage of patients achieved normokalemia after a week. Then, after achieving normokalemia, SZC reduced potassium during days 8 through 29 in a dosedependent way $(73,78)$. The ENERGIZE trial tested SZC in patients admitted at the Emergency Department (ED) with acute hyperkalemia. SZC was administered up to three times during 10-h, in association with insulin and glucose compared to placebo. Reductions in potassium levels at $1 \mathrm{~h}$ with SZC or the placebo were similar, probably due to the predominant potassium-lowering effect of the concomitant insulin and glucose treatment, but a greater reduction in mean potassium was observed in the SZC compared with the placebo at $2 \mathrm{~h}$ suggesting the beneficial role of SZC in the emergency treatment of hyperkalemia (72).

The ZS-005 trial tested the long-term efficacy and safety of SZC in 751 outpatients with hyperkalemia. Ninety-nine percentage of the patients achieved potassium of 3.5-5.5 $\mathrm{mmol} / \mathrm{L}$ in the correction phase, while more than $90 \%$ of the patients achieved a normal potassium level after 12 months of treatment (77).

In hyperkalemic patients undergoing hemodialysis, oncedaily SZC on non-dialysis days effectively maintained predialysis serum potassium levels on three out of four dialysis treatments, after long interdialytic period without rescue treatment over 8 weeks in the DIALIZE study. Interestingly, adverse effects, including interdialytic weight gain, were similar between the two groups (71). The ongoing PRIORITIZE-HF trial (estimated to end in 2020) (NCT03532009) will evaluate the effect of SZC compared to placebo in patients with HF taking RAASi.

SZC is dosed $10 \mathrm{mg}$ TID in the acute phase and dropped to $5-10 \mathrm{mg}$ daily thereafter. Given that SZC is insoluble, is not systemically absorbed and does not expand on contact with water, it is very well-tolerated.

\section{Safety and Tolerability of News Potassium Binders}

Patiromer and SZC are generally well-tolerated. Overall, Patiromer related adverse events occurred in $\sim 20 \%$ of the patients enrolled the major trials (54). These events include electrolyte disorders, such as hypomagnesemia and hypokalemia, and mild gastrointestinal symptoms, such as constipation (8\%), diarrhea (5\%), nausea and flatulence (65). Monitoring serum magnesium is recommended, considering supplementations for patients who develop hypomagnesemia while on patiromer (86). In vitro studies indicated that Patiromer may interact with some medications like ciprofloxacin, levothyroxine and metformin
(87). Therefore, the administration of other oral medications at least $3 \mathrm{~h}$ before or $3 \mathrm{~h}$ after Patiromer is recommended.

SZC has not been associated with any serious adverse effects in RCTs. The most common were hypokalemia (5.8\% of patients enrolled in different studies) and a dose-dependent increase in edema (88) cause because its sodium content. Monitoring signs of edema, especially in patients at risk of fluid overload, such CKD and CHF patients is recommended, and adjusting dietary salt intake and the dose of diuretics is probably required (89). In phase 2 and 3 trials, the incidence of gastrointestinal adverse events (nausea, constipation, vomiting or diarrhea) was similar between the treated group and the placebo group. However, as for patiromer, SZC should also not be used in patients with severe constipation, bowel obstructions or impaction, including abnormal postoperative bowel motility disorders. Because SZC may affect absorption of other oral medications with $\mathrm{pH}$ dependent solubility due to a transient increase in gastric $\mathrm{pH}$, SZC administration should be separated from these medications by at least $2 \mathrm{~h}(85)$,

\section{SUMMARY}

Hyperkalemia is a common complication in patients with comorbidities (CKD, diabetes, $\mathrm{HF}$ ) and among those taking certain critical medications (RAASi and MRAs). The frequency and severity of hyperkalemia increases during CKD progression, and is associated with higher mortality. As RAAS inhibition augments the risk of hyperkalemia, improvement in potassium control could allow enhancing RAAS inhibitor use in patients with an evidence-based indication. Cation exchange resins used to treat hyperkalemia are unsuitable for long-term use owing to gastrointestinal side effects. Newer potassium-lowering therapies (Patiromer and SZC) can effectively and safely correct hyperkalemia and maintain normokalemia in patients with co-morbidities receiving RAASi therapy. The long-term efficacy and safety of newer potassium-binders remains to be ascertained. However, their use for cardiovascular and renal risk reduction in combination with RAASi therapy holds promise for renal and cardiovascular protection in non ND-CKD patients. Nowadays this represents one of the most important news released to the renal community.

\section{AUTHOR CONTRIBUTIONS}

EM, PC, and JM contributed equally in the writing and reviewing the paper. All authors contributed to the article and approved the submitted version.

\section{ACKNOWLEDGMENTS}

The authors would like to thank Cayetana Mate as the designer of the figures in this manuscript. 


\section{REFERENCES}

1. Palmer BF. Regulation of potassium homeostasis. Clin J Am Soc Nephrol. (2015) 10:1050-60. doi: 10.2215/CJN.08580813

2. Gumz ML, Rabinowitz L, Wingo CS. An integrated view of potassium homeostasis. N Engl J Med. (2015) 373:1787-8. doi: 10.1056/NEJMc15 09656

3. Kalantar-Zadeh K, Fouque D. Nutritional management of chronic kidney disease. N Engl J Med. (2017) 377:1765-76. doi: 10.1056/NEJMra1700312

4. Borrelli S, De Nicola L, Minutolo R, Conte, G, Chiodini, et al. Current management of hyperkalemia in non-dialysis CKD: longitudinal study of patients receiving stable nephrology care. Nutrients. (2021) 13:942. doi: 10.3390/nu13030942

5. Epstein M, Lifschitz MD. Potassium homeostasis and dyskalemias: the respective roles of renal, extrarenal, and gut sensors in potassium handling. Kidney Int Suppl. (2016) 6:7-15. doi: 10.1016/j.kisu.2016.01.006

6. Kovesdy CP. Management of hyperkalaemia in chronic kidney disease. Nat Rev Nephrol. (2014) 10:653-62. doi: 10.1038/nrneph.2014.168

7. Hoorn EJ, Gritter M, Cuevas CA, Fenton RA. Regulation of the renal $\mathrm{NaCl}$ cotransporter and its role in potassium homeostasis. Physiol Rev. (2020) 100:321-56. doi: 10.1152/physrev.00044.2018

8. Palmer BF, Clegg DJ. Physiology and pathophysiology of potassium homeostasis. Adv Physiol Educ. (2016) 40:48090. doi: 10.1152/advan.00121.2016

9. Clase CM, Carrero JJ, Ellison DH, Grams ME, Hemmelgarn BR, Jardine $\mathrm{MJ}$ et al. Potassium homeostasis and management of dyskalemia in kidney diseases: conclusions from a Kidney Disease: Improving Global Outcomes (KDIGO) controversies conference. Kidney Int. (2020) 97:4261. doi: 10.1016/j.kint.2019.09.018

10. Rabinowitz L, Sarason RL, Yamauchi H. Effect of aldosterone on potassium excretion during potassium chloride infusion in sheep. Am J Physiol. (1985) 249:R455-61. doi: 10.1152/ajpregu.1985.249.4.R455

11. Cases A, Cigarrán-Guldrís S, Mas S, Gonzalez-Parra E. Vegetable-based diets for chronic kidney disease? It is time to reconsider. Nutrients. (2019) 11:1263. doi: 10.3390/nu11061263

12. Cupisti A, Kovesdy CP, D’Alessandro C, Kalantar-Zadeh K. Dietary approach to recurrent or chronic hyperkalaemia in patients with decreased kidney function. Nutrients. (2018) 10:261. doi: 10.3390/nu10030261

13. Belmar Vega L, Galabia ER, Bada da Silva J, Bentanachs González M, Fernández Fresnedo G, Piñera Haces C, et al. Epidemiology of hyperkalemia in chronic kidney disease. Nefrologia. (2019) 39:277-86. doi: 10.1016/j.nefroe.2018.11.014

14. De Nicola L, Di Lullo L, Paoletti E, Cupisti A, Bianchi S. Chronic hyperkalemia in non-dialysis CKD: controversial issues in nephrology practice. J Nephrol. (2018) 31:653-64. doi: 10.1007/s40620-018-0502-6

15. Kovesdy CP, Matsushita K, Sang Y, Brunskill NJ, Carrero JJ, Chodick G, et al. Serum potassium and adverse outcomes across the range of kidney function: a CKD Prognosis Consortium meta-analysis. Eur Heart J. (2018) 39:1535-42. doi: 10.1093/eurheartj/ehy100

16. Nakhoul GN, Huang H, Arrigain S, Jolly S E, Schold JD, Nall, et al. Serum potassium, end-stage renal disease and mortality in chronic kidney disease. Am J Nephrol. (2015) 41:456-63. doi: 10.1159/000437151

17. Provenzano M, De Francesco M, Iannazzo S Garofalo C, Andreucci M, Genualdo R, et al. Cost-analysis of persistent hyperkalaemia in non-dialysis chronic kidney disease patients under nephrology care in Italy. Int J Clin Pract. (2020) 74:e13475. doi: 10.1111/ijcp.13475

18. Provenzano M, Minutolo R, Chiodini P, Bellizzi V, Nappi F, Russo D, et al. Competing-risk analysis of death and end stage kidney disease by hyperkalaemia status in non-dialysis chronic kidney disease patients receiving stable nephrology care. J Clin Med. (2018) 7:499. doi: 10.3390/jcm7120499

19. Palmer BF, Carrero JJ, Clegg DJ, Colbert GB, Emmett M, Fishbane S, et al. Clinical management of hyperkalemia. Mayo Clin Proc. (2021) 96:74462. doi: 10.1016/j.mayocp.2020.06.014

20. Betts KA, Woolley JM, Mu F, Wang Y, Dua A, Wu EQ. Postdischarge health care costs and readmission in patients with hyperkalemia-related hospitalizations. Kidney Int Rep. (2020) 5:1280-90. doi: 10.1016/j.ekir.2020.06.004
21. Olry de Labry Lima A, Díaz Castro O, Romero-Requena JM, García DíazGuerr, M, Arroyo Pineda V, et al. Hyperkalaemia management and related costs in chronic kidney disease patients with comorbidities in Spain. Clin Kidney J. (2021). doi: 10.1093/ckj/sfab076

22. Pochineni V, Rondon-Berrios H. Electrolyte and acid-base disorders in the renal transplant recipient. Front Med. (2018) 5:261. doi: 10.3389/fmed.2018.00261

23. Rizk J, Quan D, Gabardi S, Rizk Y, Kalantar-Zadeh K. Novel approaches to management of hyperkalaemia in kidney transplantation. Curr Opin Nephrol Hypertens. (2021) 30:27-37. doi: 10.1097/MNH.0000000000000657

24. Deppe CE, Heering PJ, Viengchareun S, Grabensee B, Farman N, Lombès M. Cyclosporine a and FK506 inhibit transcriptional activity of the human mineralocorticoid receptor: a cell-based model to investigate partial aldosterone resistance in kidney transplantation. Endocrinology. (2002) 143:1932-41. doi: 10.1210/endo.143.5.8821

25. Shin JI, Palta M, Djamali A, Kaufman DB, Astor BC. The association between renin-angiotensin system blockade and long-term outcomes in renal transplant recipients: the Wisconsin Allograft Recipient Database (WisARD). Transplantation. (2016) 100:1541-9. doi: 10.1097/TP.0000000000000938

26. Schnelle K, Winters H, Pesavento T, Singh P. Largest experience of safety and efficacy of patiromer in solid organ transplant. Transplant Direct. (2020) 6:e595. doi: 10.1097/TXD.0000000000001037

27. Lim MA, Sawinski D, Trofe-Clark J. Safety, effectiveness, and tolerability of patiromer in kidney transplant recipients. Transplantation. (2019) 103:e2812. doi: 10.1097/TP.0000000000002829

28. Rattanavich R, Malone AF, Alhamad T. Safety and efficacy of patiromer use with tacrolimus in kidney transplant recipients. Transpl Int. (2019) 32:1101. doi: $10.1111 /$ tri.13369

29. Winstead RJ, Demehin M, Yakubu I, Song C, Brown A, Levy M, et al. Sodium zirconium cyclosilicate use in solid organ transplant recipients and its effect on potassium and immunosuppression. Clin Transplant. (2020) 34:e13791. doi: 10.1111/ctr.13791

30. Williams B, Mancia G, Spiering W, Agabiti Rosei E, Azizi M, Burnie M, et al. 2018 ESC/ESH Guidelines for the management of arterial hypertension. Eur Heart J. (2018). 39:3021-104. doi: 10.1093/eurheartj/ehy339

31. Williams B, MacDonald TM, Morant SV, Webb DJ, Sever P, McInnes GT, et al. Endocrine and haemodynamic changes in resistant hypertension, and blood pressure responses to spironolactone or amiloride: the PATHWAY2 mechanisms substudies. Lancet Diabetes Endocrinol. (2018) 6:46475. doi: 10.1016/S2213-8587(18)30071-8

32. Zhao D, Liu H, Dong P, Zhao J. A meta-analysis of add-on use of spironolactone in patients with resistant hypertension. Int J Cardiol. (2017) 233:113-7. doi: 10.1016/j.ijcard.2016.12.158

33. Carey RM, Calhoun DA, Bakris GL, Brook RD, Daugherty SL, DennisonHimmelfarb CR, et al. Resistant hypertension: detection, evaluation, and management: a scientific statement from the American Heart Association. Hypertension. (2018) 72:e53-90. doi: 10.1161/HYP.0000000000000084

34. Agarwal R, Rossignol P, Romero A, Garza D, Mayo MR, Warren S, et al. Patiromer versus placebo to enable spironolactone use in patients with resistant hypertension and chronic kidney disease (AMBER): a phase 2, randomised, double-blind, placebo-controlled trial. Lancet. (2019) 394:154050. doi: 10.1016/S0140-6736(19)32135-X

35. Brenner BM, Cooper ME, de Zeeuw D, Keane WF, Mitch WE, Parving HH, et al. Effects of losartan on renal and cardiovascular outcomes in patients with type 2 diabetes and nephropathy. N Engl J Med. Sep. (2001) 345:8619. doi: 10.1056/NEJMoa011161

36. Einhorn LM, Zhan M, Hsu VD, Walker LD, Moen MF, Seliger SL, et al. The frequency of hyperkalemia and its significance in chronic kidney disease. Arch Intern Med. (2009) 169:1156-62. doi: 10.1001/archinternmed.2009.132

37. (K/DOQI) KDOQI. K/DOQI clinical practice guidelines on hypertension and antihypertensive agents in chronic kidney disease. Am J Kidney Dis. (2004) 43(5 Suppl. 1):S1-290. doi: 10.1053/j.ajkd.2004.03.003

38. Wheeler DC, Becker GJ. Summary of KDIGO guideline. what do we really know about management of blood pressure in patients with chronic kidney disease? Kidney Int. (2013) 83:377-83. doi: 10.1038/ki.2012.425

39. Schmidt M, Mansfield KE, Bhaskaran K, Nitsch D, Sørensen HT, Smeeth L, et al. Serum creatinine elevation after renin-angiotensin system 
blockade and long term cardiorenal risks: cohort study. BMJ. (2017) 356:j791. doi: 10.1136/bmj.j791

40. Fried LF, Emanuele N, Zhang JH, Brophy M, Conner TA, Duckworth W, et al. Combined angiotensin inhibition for the treatment of diabetic nephropathy. N Engl J Med. (2013) 369:1892-903. doi: 10.1056/NEJMoa1303154

41. Kloner RA, Gross C, Yuan J, Conrad A, Pergola PE. Effect of patiromer in hyperkalemic patients taking and not taking RAAS inhibitors. J Cardiovasc Pharmacol Ther. (2018) 23:524-31. doi: 10.1177/1074248418788334

42. Parving HH, Brenner BM, McMurray JJ, de Zeeuw D, Haffner SM, Solomon $\mathrm{SD}$, et al. Cardiorenal end points in a trial of aliskiren for type 2 diabetes. $N$ Engl J Med. (2012) 367:2204-13. doi: 10.1056/NEJMoa1208799

43. McMurray JJ, Packer M, Desai AS, Gong J, Lefkowitz MP, Rizkala AR, et al. Angiotensin-neprilysin inhibition versus enalapril in heart failure. $N$ Engl $J$ Med. (2014) 371:993-1004. doi: 10.1056/NEJMoa1409077

44. Bandak G, Sang Y, Gasparini A, Chang AR, Ballew SH, Evans M, et al. Hyperkalemia after initiating renin-angiotensin system blockade: The Stockholm Creatinine Measurements (SCREAM) project. J Am Heart Assoc. (2017) 6:e005428. doi: 10.1161/JAHA.116.005428

45. Kashihara N, Kohsaka S, Kanda E, Okami S, Yajima T. Hyperkalemia in realworld patients under continuous medical care in Japan. Kidney Int Rep. (2019) 4:1248-60. doi: 10.1016/j.ekir.2019.05.018

46. Bolignano D, Palmer SC, Navaneethan SD, Strippoli GF. Aldosterone antagonists for preventing the progression of chronic kidney disease. Cochrane Database Syst Rev. (2014) 29:CD007004. doi: 10.1002/14651858.CD007004.pub3

47. Wetmore JB, Yan H, Horne L, Peng Y, Gilbertson DT. Risk of hyperkalemia from renin-angiotensin-aldosterone system inhibitors and factors associated with treatment discontinuities in a real-world population. Nephrol Dial Transplant. (2019) 36:826-39. doi: 10.1093/ndt/gfz263

48. Fu EL, Clase CM, Evans M, Lindholm B, Rotmans JI, Dekker FW, et al. Comparative effectiveness of renin-angiotensin system inhibitors and calcium channel blockers in individuals with advanced CKD: a nationwide observational cohort study. Am J Kidney Dis. (2020) 77:71929.e1. doi: 10.1053/j.ajkd.2020.10.006

49. Kovesdy CP. Updates in hyperkalemia: outcomes and therapeutic strategies. Rev Endocr Metab Disord. (2017) 18:41-7. doi: 10.1007/s11154-016-9384-x

50. Bianchi S, Aucella F, De Nicola L, Genovesi S, Paoletti E, Regolisti G. Management of hyperkalemia in patients with kidney disease: a position paper endorsed by the Italian Society of Nephrology. J Nephrol. (2019) 32:499-516. doi: 10.1007/s40620-019-00617-y

51. Gritter M, Vogt L, Yeung SMH, Wouda RD, Ramakers CR, de Borst MH, et al. Rationale and design of a randomized placebo-controlled clinical trial assessing the renoprotective effects of potassium supplementation in chronic kidney disease. Nephron. (2018) 140:48-57. doi: 10.1159/000490261

52. Sussman EJ, Singh B, Clegg D, Palmer BF, Kalantar-Zadeh K. Let them eat healthy: can emerging potassium binders help overcome dietary potassium restrictions in chronic kidney disease? J Ren Nutr. (2020) 30:47583. doi: $10.1053 /$ j.jrn.2020.01.022

53. Batlle D, Boobés K, Manjee KG. The colon as the potassium target: entering the colonic age of hyperkalemia treatment? EBioMedicine. (2015) 2:15623. doi: 10.1016/j.ebiom.2015.10.027

54. Natale P, Palmer SC, Ruospo M, Saglimbene VM, Strippoli GF. Potassium binders for chronic hyperkalaemia in people with chronic kidney disease. Cochrane Database Syst Rev. (2020) 6:CD013165. doi: 10.1002/14651858.CD013165.pub2

55. Lepage L, Dufour AC, Doiron J, Handfield K, Desforges K, Bell R, et al. Randomized clinical trial of sodium polystyrene sulfonate for the treatment of mild hyperkalemia in CKD. Clin J Am Soc Nephrol. (2015) 10:213642. doi: 10.2215/CJN.03640415

56. Gruy-Kapral C, Emmett M, Santa Ana CA, Porter JL, Fordtran JS, Fine $\mathrm{KD}$. Effect of single dose resin-cathartic therapy on serum potassium concentration in patients with end-stage renal disease. J Am Soc Nephrol. (1998) 9:1924-30. doi: 10.1681/ASN.V9101924

57. Nakayama Y, Ueda K, Yamagishi SI, Sugiyama M, Yoshida C, Kurokawa $\mathrm{Y}$, et al. Compared effects of calcium and sodium polystyrene sulfonate on mineral and bone metabolism and volume overload in pre-dialysis patients with hyperkalemia. Clin Exp Nephrol. (2018) 22:35-44. doi: 10.1007/s10157-017-1412-y
58. Nasir K, Ahmad A. Treatment of hyperkalemia in patients with chronic kidney disease: a comparison of calcium polystyrene sulphonate and sodium polystyrene sulphonate. J Ayub Med Coll Abbottabad. (2014) 26:455-8.

59. Wang J, Lv MM, Zach O, Wang LY, Zhou MY, Song GR, et al. Calciumpolystyrene sulfonate decreases inter-dialytic hyperkalemia in patients undergoing maintenance hemodialysis: a prospective, randomized, crossover study. Ther Apher Dial. (2018) 22:609-16. doi: 10.1111/1744-9987.12723

60. Watson MA, Baker TP, Nguyen A, Sebastianelli ME, Stewart HL Oliver DK, et al. Association of prescription of oral sodium polystyrene sulfonate with sorbitol in an inpatient setting with colonic necrosis: a retrospective cohort study. Am J Kidney Dis. (2012) 60:409-16. doi: 10.1053/j.ajkd.2012.04.023

61. Wong SWS, Zhang G, Norman P, Welihinda H, Wijeratne DT. Polysulfonate resins in hyperkalemia: a systematic review. Can J Kidney Health Dis. (2020) 7:2054358120965838. doi: 10.1177/2054358120965838

62. Noel JA, Bota SE, Petrcich W, Garg AX, Carrero JJ, Harel Z, et al. Risk of hospitalization for serious adverse gastrointestinal events associated with sodium polystyrene sulfonate use in patients of advanced age. JAMA Intern Med. (2019) 179:1025-33. doi: 10.1001/jamainternmed.2019.0631

63. Laureati P, Xu Y, Trevisan M, Schalin L, Mariani I, Bellocco R, et al. Initiation of sodium polystyrene sulphonate and the risk of gastrointestinal adverse events in advanced chronic kidney disease: a nationwide study. Nephrol Dial Transplant. (2020) 35:1518-26. doi: 10.1093/ndt/gfz150

64. Yu MY, Yeo JH, Park JS, Lee CH, Kim GH. Long-term efficacy of oral calcium polystyrene sulfonate for hyperkalemia in CKD patients. PLoS ONE. (2017) 12:e0173542. doi: 10.1371/journal.pone. 0173542

65. Pitt B, Anker SD, Bushinsky DA, Kitzman DW, Zannad F, Huang IZ, et al. Evaluation of the efficacy and safety of RLY5016, a polymeric potassium binder, in a double-blind, placebo-controlled study in patients with chronic heart failure (the PEARL-HF) trial. Eur Heart J. (2011) 32:8208. doi: 10.1093/eurheartj/ehq502

66. Weir MR, Bakris GL, Bushinsky DA, Mayo MR, Garza D, Stasiv Y, et al. Patiromer in patients with kidney disease and hyperkalemia receiving RAAS inhibitors. N Engl J Med. (2015) 372:211-21. doi: 10.1056/NEJMoa1410853

67. Bakris GL, Pitt B, Weir MR, Freeman MW, Mayo MR, Garza D, et al. Effect of patiromer on serum potassium level in patients with hyperkalemia and diabetic kidney disease: the AMETHYST-DN randomized clinical trial. JAMA. (2015) 314:151-61. doi: 10.1001/jama.2015.7446

68. PEARL-HD. Patiromer Efficacy to Reduce Episodic Hyperkalemia in ESRD Patients Treated With Hemodyalisis (PEARL-HD) Duke University, (2021).

69. Rafique Z, Liu M, Staggers KA, Minard CG, Peacock WF. Patiromer for treatment of hyperkalemia in the emergency department: a pilot study. Acad Emerg Med. (2020) 27:54-60. doi: 10.1111/acem.13868

70. Ash SR, Singh B, Lavin PT, Stavros F, Rasmussen HS. A phase 2 study on the treatment of hyperkalemia in patients with chronic kidney disease suggests that the selective potassium trap, ZS-9, is safe and efficient. Kidney Int. (2015) 88:404-11. doi: 10.1038/ki.2014.382

71. Fishbane S, Ford M, Fukagawa M, McCafferty K, Rastogi A, Spinowitz, et al. A phase $3 \mathrm{~b}$, randomized, double-blind, placebo-controlled study of sodium zirconium cyclosilicate for reducing the incidence of predialysis hyperkalemia. J Am Soc Nephrol. (2019) 30:1723-33. doi: 10.1681/ASN.2019050450

72. Peacock WF, Rafique Z, Vishnevskiy K, Michelson E, Vishneva E, Zvereva $\mathrm{T}$, et al. Emergency potassium normalization treatment including sodium zirconium cyclosilicate: a phase II, randomized, double-blind, placebo-controlled study (ENERGIZE). Acad Emerg Med. (2020) 27:47586. doi: $10.1111 /$ acem.13954

73. Kosiborod M, Rasmussen HS, Lavin P, Qunibi WY, Spinowitz B, Packham D, et al. Effect of sodium zirconium cyclosilicate on potassium lowering for 28 days among outpatients with hyperkalemia: the HARMONIZE randomized clinical trial. JAMA. (2014) 312:2223-33. doi: 10.1001/jama.2014.15688

74. Anker SD, Kosiborod M, Zannad F, Piña IL, McCullough PA, Filippatos G, et al. Maintenance of serum potassium with sodium zirconium cyclosilicate (ZS-9) in heart failure patients: results from a phase 3 randomized, double-blind, placebo-controlled trial. Eur J Heart Fail. (2015) 17:10506. doi: $10.1002 /$ ejhf.300

75. Packham DK, Rasmussen HS, Lavin PT, El-Shahawy MA, Roger SD, Block G, et al. Sodium zirconium cyclosilicate in hyperkalemia. N Engl J Med. (2015) 372:222-31. doi: 10.1056/NEJMoa1411487 
76. Kashihara N, Yamasaki Y, Osonoi T, Harada H, Shibagaki Y, Zhao $\mathrm{J}$, et al. A phase 3 multicenter open-label maintenance study to investigate the long-term safety of sodium zirconium cyclosilicate in Japanese subjects with hyperkalemia. Clin Exp Nephrol. (2020) 25:140-9. doi: 10.1007/s10157-020-01972-y

77. Spinowitz BS, Fishbane S, Pergola PE, Roger S, Lerma EV, Butler J, et al. Sodium zirconium cyclosilicate among individuals with hyperkalemia: a 12-month Phase 3 study. Clin J Am Soc Nephrol. (2019) 14:798809. doi: 10.2215/CJN.12651018

78. Roger SD, Lavin PT, Lerma EV, McCullough P, Butler J, Spinowitz BS, et al. Long-term safety and efficacy of sodium zirconium cyclosilicate for hyperkalaemia in patients with mild/moderate versus severe/end-stage chronic kidney disease: comparative results from an open-label, Phase 3 study. Nephrol Dial Transplant. (2020) 36:137-50. doi: 10.1093/ndt/gfz285

79. Veltassa Ficha Tecnica ${ }^{\circledR}$ (CEM A [1995-2019].

80. Li L, Harrison SD, Cope MJ, Park C, Lee L, Salaymeh F, et al. Mechanism of action and pharmacology of patiromer, a nonabsorbed cross-linked polymer that lowers serum potassium concentration in patients with hyperkalemia. J Cardiovasc Pharmacol Ther. (2016) 21:45665. doi: 10.1177/1074248416629549

81. Bushinsky DA, Spiegel DM, Gross C, Benton WW, Fogli J, Hill Gallan, et al. Effect of patiromer on urinary ion excretion in healthy adults. Clin J Am Soc Nephrol. (2016) 11:1769-76. doi: 10.2215/CJN.01170216

82. Weir MR, Mayo MR, Garza D, Arthur SA, Berman L, Bushinsky D, et al. Effectiveness of patiromer in the treatment of hyperkalemia in chronic kidney disease patients with hypertension on diuretics. J Hypertens. (2017) 35(Suppl. 1):S57-63. doi: 10.1097/HJH.0000000000001278

83. Weir MR, Bakris GL, Gross C, Mayo, MR, Garza D, Stasiv Y, et al. Treatment with patiromer decreases aldosterone in patients with chronic kidney disease and hyperkalemia on renin-angiotensin system inhibitors. Kidney Int. (2016) 90:696-704. doi: 10.1016/j.kint.2016.04.019
84. Study D. Available online at: https://clinicaltrials.gov/ct2/show/NCT03888066 85. Lokelma Ficha técnica ${ }^{\circledR}$ (C) EM A [1995-2019].

86. Pitt B, Garza D. The tolerability and safety profile of patiromer: a novel polymer-based potassium binder for the treatment of hyperkalemia. Expert Opin Drug Saf. (2018) 17:525-35. doi: 10.1080/14740338.2018.14 62335

87. Lesko LJ, Offman E, Brew CT, Garza D, Benton W, Mayo MR, et al. Evaluation of the potential for drug interactions with patiromer in healthy volunteers. J Cardiovasc Pharmacol Ther. (2017) 22:43446. doi: 10.1177/1074248417691135

88. Packham DK, Rasmussen HS, Singh B. New agents for hyperkalemia. $N$ Engl J Med. (2015) 372:1571-2. doi: 10.1056/NEJMc15 01933

89. Hoy SM. Sodium zirconium cyclosilicate: a review in hyperkalaemia. Drugs. (2018) 78:1605-13. doi: 10.1007/s40265-0180991-6

Conflict of Interest: EM and JM report serving as consultants participating in advisory boards for Vifor Pharma Group Company.

The remaining author declares that the research was conducted in the absence of any commercial or financial relationships that could be construed as a potential conflict of interest.

Copyright (c) 2021 Morales, Cravedi and Manrique. This is an open-access article distributed under the terms of the Creative Commons Attribution License (CC BY). The use, distribution or reproduction in other forums is permitted, provided the original author(s) and the copyright owner(s) are credited and that the original publication in this journal is cited, in accordance with accepted academic practice. No use, distribution or reproduction is permitted which does not comply with these terms. 